\title{
Case Study: \\ Decline In CIS/IT Degree \\ Enrollment At A Medium-Sized University
}

Gary Alan Davis, (E-mail: davis@rmu.edu), Robert Morris University G. James Leone, (E-mail: leone@rmu.edu), Robert Morris University

\begin{abstract}
Within the past few years, colleges and universities in the United States and worldwide have noted a marked decline in the number of students enrolling in Computer and Information Systems (CIS) and Information Technology (IT) degree programs. With the potential for a rebounding U.S. economy, this shortage of new CIS and IT professionals gives cause for concern. The goal of the present research was to analyze CIS and IT enrollment trends at Robert Morris University and determine appropriate courses of action for meeting the anticipated demand for CIS/IT graduates. The study involved comparative and forecast analyses using actual student enrollment statistics and U.S. Department of Labor statistics. Forecast projections were determined out to and including the year 2013. The findings of the research suggest that CIS and IT degree enrollment at Robert Morris University lags associated employment trends in CIS/IT-related fields. Further, the findings parallel the analyses of other institutes of higher education, in which CIS/IT student enrollment projections are indicative of a shortage of information professionals over the next ten years. Based on the findings of the present study, the authors make several recommendations to Robert Morris University faculty and administration regarding strategies to address the ensuing CIS/IT skills gap.
\end{abstract}

\subsection{INTRODUCTION}

olleges and universities worldwide have noted a marked decline in the number of Computer and Information Systems (CIS) and Information Technology (IT) degrees conferred upon graduates (3). This decline in conferred degrees is most alarming when an increase in demand for CIS/IT-related positions is considered. With the potential of a rebounding economy and a possible resurgence of CIS/IT-related employment, the skills gap between available positions and available college graduates becomes a noteworthy topic for discussion and academic research.

\subsection{Background}

Prevailing business conditions have historically influenced high school graduates entering college degree programs (2). CIS and IT-related fields, once very attractive career paths, have suddenly become undesirable professions in the wake of massive corporate layoffs and widespread downsizing. Entering college freshmen have reacted to the downturn in technology-related positions by “ . . . voting with their feet and going on [to] courses they feel are more likely to lead to jobs" (3).

In the U.S. during the 1900s, the ten largest companies were tied to agriculture or the burgeoning industrial revolution. During the 1990 s, however, the ten largest companies were " . . . industrial, retail, or based in information technology" (2). In the 1990s, college freshman eagerly opted for CIS/IT-related degrees that would open employment doors. Enrollment in CIS/IT degrees seems to have peaked during the 2000-2001 academic year: During that year, nearly 42,000 CIS/IT bachelor's degrees were conferred in the United States alone. More specifically, the 2000-2001 academic year marked a 40 percent increase over the number of CIS/IT degrees awarded 
just ten years prior (10). During the past several years, however, the enrollment in CIS/IT degree programs has taken a downturn; as much as a 12 percent decrease in 2004 compared to enrollment in 2003 (3). The decline in CIS/IT degree enrollment is in sharp contrast to the current and predicted demand for qualified graduates needed to fill CIS and IT positions. A recent META Group study estimates that “ . . . current IT skill demand exceeds supply by 20 to 25 percent and is expected to grow to 30 to 35 percent during the next five years" (9).

The CIS/IT skills gap has been further exacerbated by the events since September 11, 2001. Since that time, thousands of National Guard and U.S. Military Reserves have been called to active duty. The absence of these fighting men and women constitutes yet "... another drain on the available IT work force" (9).

Finally, the aging demographic of the current CIS and IT workforce offers yet another hurdle in the battle to maintain qualified technology professionals. Aging baby boomers will most likely opt to retire over the next several years, further increasing the demand for new CIS and IT graduates. According to author Kathleen Melymuka:

The retirement of baby boomers will bring a number of challenges, including a shortage of the kind of IT skills that can't be outsourced. . . if the baby boomers were to retire on schedule and en masse, there aren't enough younger workers up to speed to take their place. (6)

\subsection{Significance of Research}

Research into the technology skills gap and the decline in the conferment of CIS and IT degrees is of particular interest to academics, employers, and anyone who may have an interest in an CIS or IT-related career. Information professionals serve three vital functions in our modern workforce: 1) they provide support to business operations, 2) they facilitate faster and better decision making capabilities via advanced decision support systems (DSS), and 3) they provide their employers with strategic competitive advantage (9). As businesses face a shortage of qualified information professionals, the ability to provide these three vital business functions is threatened.

Since the terrorist attacks in 2001, information security has been a priority for both public and private sector organizations. The decline of CIS and IT graduates also means a smaller pool of qualified professionals available to enter “cybersecurity" professions. According to Dr. Eugene Spafford, director of Purdue University's Center for Education and Research in Information Assurance and Security (CERIAS), "The United States faces a growing shortage of information security professionals" (7). A recent study entitled, "The Cyber Defense IQ Report" by Brainbench concurs, ". . . certified cyberprofessionals [are] needed in specialties such as network security, disaster recovery and planning, and wireless area network technologies" (7). The same study revealed that one of the reasons that many organizations are not as prepared as they should be is because "... there is a relatively small number of certified disaster recovery professionals across the nation" (7). The lack of qualified staff among the myriad of information security positions places increased burdens on current staff and increases the information vulnerability of both public and private sector organizations.

Many organizations have turned to offshore outsourcing as a means to offset the current and predicted shortage of technology skills (12). At first glance, offshore outsourcing seems too good to be true; American companies have scrambled to take advantage of other countries' abundant supply of highly skilled workers. Outsourcing companies in the United States have found that they can employ foreign technology workers at ten percent of the cost of American workers (4). Many U.S. firms, however, are discovering the hidden costs associated with offshore outsourcing; hidden costs such as low productivity, which can be as low as one sixth the productivity of U.S.-based efforts (8). Many U.S. firms are also finding that increased offshore outsourcing leads to increased vulnerability to information security threats. Author Edward Sujdak warns:

The outsourcing of program, application and database development is certainly a possibility; however, there is a significant security issue regarding the loss or destruction of data and information. Finally, the threat of introducing malicious code by an offshore developer may pose an unnecessary risk. (9) 


\subsection{Research Question}

The recent economic recession, high unemployment, and popularity of offshore outsourcing have undoubtedly tainted CIS and IT professions. One negative impact after another has taken its toll on technologyrelated fields, forcing college freshmen to reasonably avoid CIS and IT degrees. As technology author Bill Goodwin remarked, "The whole image of IT is a problem" (3).

The recession, however, cannot last indefinitely. As the U.S. economy recovers, CIS and IT professionals will again be in high demand. Economic and employment indicators forecast an increased demand in information and technology-related fields. If these forecasts prove accurate, will the supply of CIS/IT graduates from Robert Morris University be sufficient to keep pace with the industry demand for CIS/IT professionals? Author Bill Leonard summarizes this noteworthy concern:

Revenue growth in the IT industry stalled in the past year, and now we know that IT employment lost ground. We believe the situation to be short-lived, with employers filling positions they were forced to cut in the recession. However, many [unemployed] workers just don't have the skills employers are now demanding. (5)

\subsection{RESEARCH METHODS}

The current research involved a case study of a medium-sized, private university in Southwestern Pennsylvania. The school, Robert Morris University, was founded in 1921 and offers undergraduate, graduate, and doctoral degrees to nearly 5,000 students distributed across multiple campuses in and around the Pittsburgh area. Robert Morris University, like many other institutions of higher education, has noted a marked decline in the number of students enrolling in its undergraduate Information Sciences (IS) and Information Systems Management (ISM) degrees and its graduate Communications and Information Systems and Information Systems Management degrees.

In the current case study, undergraduate IS/ISM enrollment data dating back to 1995 were examined. The enrollment data, including the current decline in enrollment, were forecast out ten years to 2013. The enrollment data were forecast using the least squares, linear trend method. The forecast enrollment data were then compared to forecast demand data for CIS/IT-related positions provided by the U.S. Bureau of Labor Statistics. The comparison was made to determine the current and predicted trend in CIS student enrollment at Robert Morris University, as compared to the trend in CIS/IT employment.

\subsection{DATA ANALYSIS}

U.S. employment data are presented in Table 1. The data are provided by the U.S. Department of Labor, Bureau of Labor Statistics (11). The data query was obtained via the U.S. Department of Labor web site on July 12, 2004. Specifically, Table 1 shows the number of employees that were on non-farm payrolls during the years 1995 to 2003. The results in Table 1 have been further filtered by Industry Super Sector equal to 'Information' and Industry equal to 'Information' (NAICS Sector 51). The data have been adjusted for seasonality.

The results in Table 1 are actual employee headcounts (in thousands) for years 1995 through 2003. The employee headcounts for years 2004 through 2013 have been forecast using the least squares, linear trend method. It should be noted that 2004 employment figures were not complete at the time of this study, and therefore, have been forecast using the least squares method. 
Table 1: U.S. Employees by Industry Sector and Selected Industry Detail

\begin{tabular}{lc}
\hline Year & Employees (Thousands) \\
1995 & 2844 \\
1996 & 2940 \\
1997 & 3084 \\
1998 & 3219 \\
1999 & 3418 \\
2000 & 3630 \\
2001 & 3629 \\
2002 & 3394 \\
2003 & 3198 \\
2004 & 2735 \\
2005 & 2855 \\
2006 & 2926 \\
2007 & 2970 \\
2008 & 2998 \\
2009 & 3017 \\
2010 & 3030 \\
2011 & 3039 \\
2012 & 3045 \\
2013 & 3049 \\
\hline
\end{tabular}

Robert Morris University freshman application data are presented in Table 2. The results in Table 2 include applications to the following two undergraduate programs at RMU: Bachelor of Science in Information Sciences (IS) and Bachelor of Science in Information Systems Management (ISM).

Table 2: Applicants for IS and ISM undergraduate programs at Robert Morris University

\begin{tabular}{lc}
\hline Year & Student Applicants \\
1995 & 90 \\
1996 & 52 \\
1997 & 81 \\
1998 & 109 \\
1999 & 153 \\
2000 & 180 \\
2001 & 230 \\
2002 & 248 \\
2003 & 152 \\
2004 & 129 \\
2005 & 80 \\
2006 & 99 \\
2007 & 110 \\
2008 & 116 \\
2009 & 120 \\
2010 & 122 \\
2011 & 124 \\
2013 & 125 \\
\hline
\end{tabular}


Similar to the Department of Labor results in Table 1, the student counts in Table 2 are a combination of actual and forecast data. The results in Table 2 are actual counts of freshman applications for years 1995 through 2004. The results for years 2005 through 2013 in Table 2 have been forecast using the least squares, linear trend method.

\subsection{FINDINGS}

The results in Table 1 reveal a steady increase in the number of CIS/IT positions from $1995(2,844,000$ jobs) up to the highest point in 2000 (3,630,000 jobs). The number of positions remains relatively constant between years 2000 (3,630,000 jobs) and 2001 (3,629,000 jobs). Beginning with year 2002, however, the number of CIS/IT positions begins to decline.

The forecast trend of all included years reveals a gradual but steady increase in the number of CIS/IT positions from year 2004 (2,735,000 jobs) to year 2013 (3,049,000 jobs). This trend in the number of available positions marks an 11.5 percent increase over the ten year span. This marked increase in available CIS/IT positions over the next ten years is consistent with employment projections made by the U.S. Department of Labor and other authors in the fields of employment and economics (5).

The trend in available CIS/IT positions from 1995 to 2013 is more obvious when viewed graphically. Figure 1 presents the U.S. Department of Labor statistics in a line graph format: The number of positions (in thousands) is presented on the $\mathrm{y}$ (vertical) axis and the time span from 1995 to 2013 is presented on the $\mathrm{x}$ (horizontal) axis. As in the tabular format of Table 1, the results for years 1995 through 2003 are actual headcounts from the U.S Department of Labor. The results for years 2004 through 2013 have been forecast using the least squares method.

Figure 1 U.S. Employees By Industry Sector And Selected Industry Detail

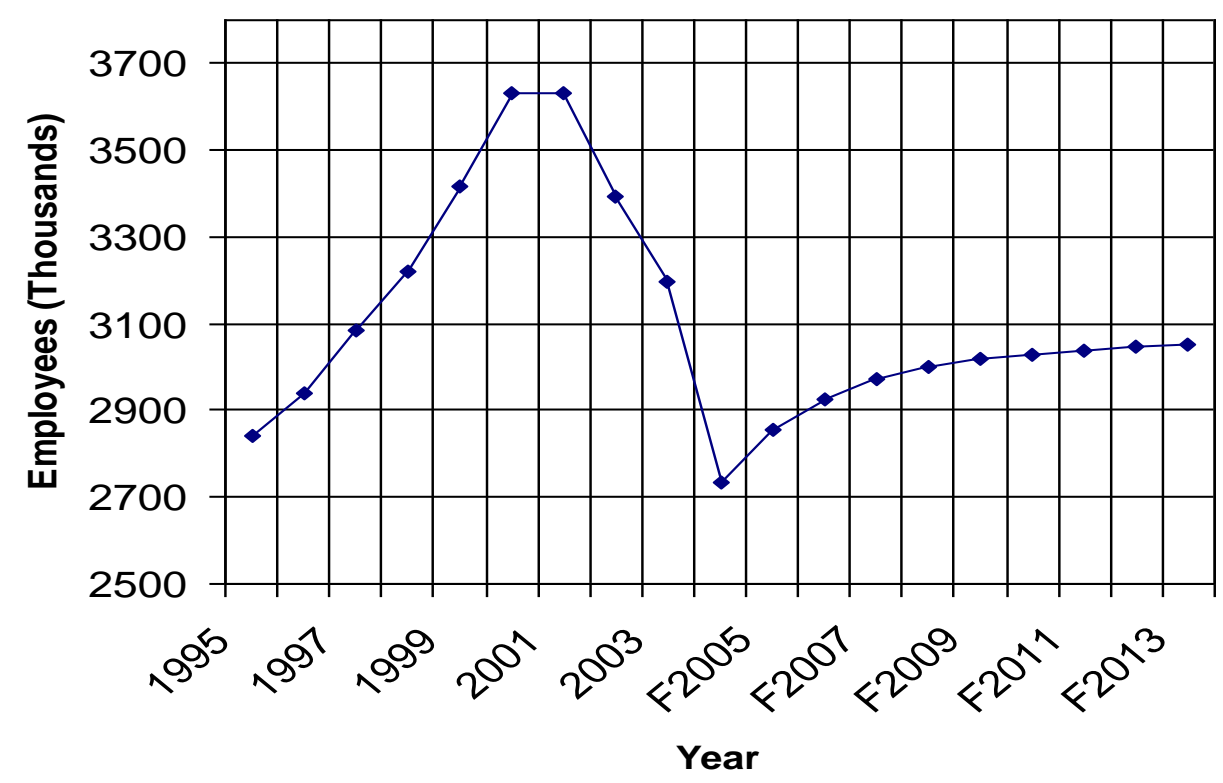


The results in Table 2 reveal a steady increase in the number of applicants to RMU's IS and ISM programs from 1995 (90 applicants) up to the highest point in 2002 (248 applicants). Beginning with 2003, the number of applicants begins to decline to a low point of 129 applicants in 2004.

Similar to the U.S. Department of Labor data, the forecast trend in applicants to RMU's IS and ISM programs reveals a slight increase in applications after year 2005; however, this increase is so gradual over the ten year span that the data actually reveal a 2.3 percent decline in applicants when the 2013 forecast data are compared to 2004 data. This extremely modest increase in student applicants is consistent with the forecasts of other authors and researchers in the field (3).

The trend in RMU's IS and ISM applicants from 1995 to 2013 is more obvious when viewed graphically. Figure 2 presents the RMU freshman application statistics in a line graph format: The number of student applications is presented on the y (vertical) axis and the time span from 1995 to 2013 is presented on the $\mathrm{x}$ (horizontal) axis. As in the tabular format of Table 2, the results for years 1995 through 2004 are actual headcounts collected by RMU's proprietary student tracking system. The results for years 2005 through 2013 have been forecast using the least squares method.

Figure 2 Applicants for IS and ISM undergraduate programs at Robert Morris University

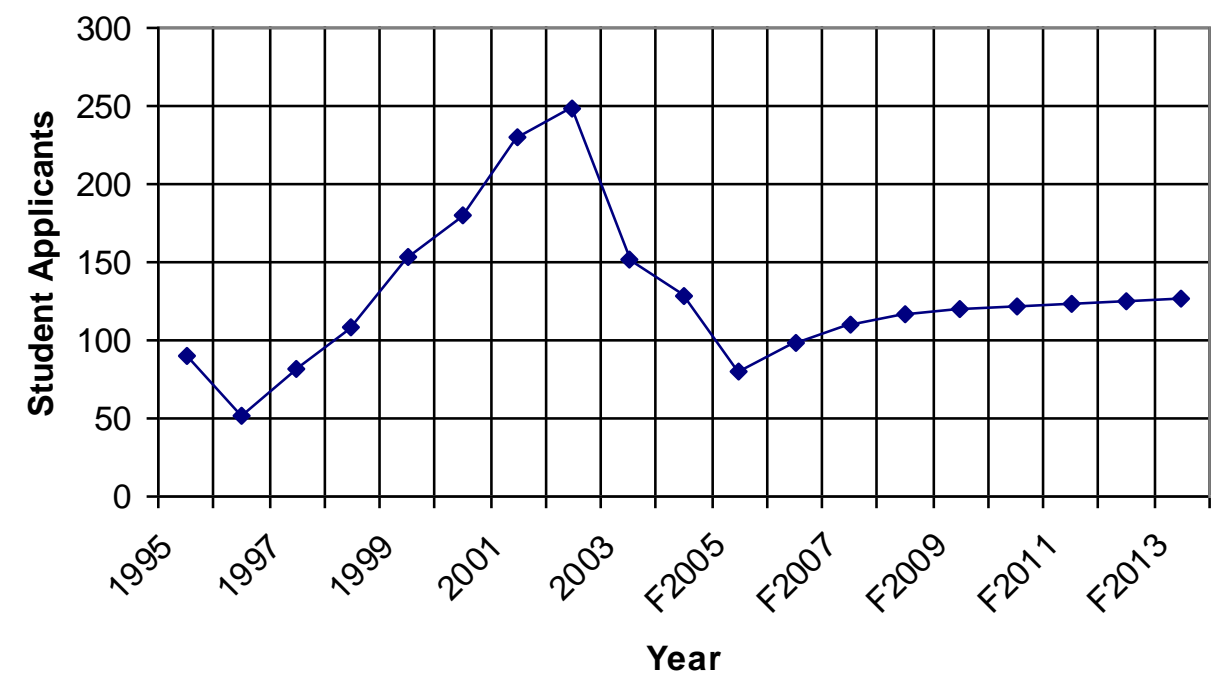

\subsection{DISCUSSION}

Using U.S. Department of Labor statistics and student enrollment data, the present case study research was conducted to determine if the current and projected supply of Robert Morris University CIS/IT graduates would be consistent with the current and projected industry demand. The analysis and forecast of U.S. Department of Labor statistics revealed that over the ten year span from 2004 to 2013, the number of CIS and IT positions within the United States will increase by nearly 12 percent. This increase in demand for CIS and IT professionals is particularly alarming when compared to the results of the Robert Morris University case study analysis. In the present case study, the analysis and forecast of applicant data revealed an over two percent decrease in the number of IS and ISM applicants during the same ten year span.

The results of the analyses suggest that enrollment trends at Robert Morris University in CIS and IT programs tend to lag behind trends in CIS and IT employment. These results closely parallel the findings of other authors and researchers, who tied CIS/IT enrollment trends to employment trends (2). If the employment forecasts 
offered by the Department of Labor prove to be correct, the number of CIS/IT graduates from Robert Morris University will not be in step with the rising industry demand.

\subsection{Recommendations}

Based on the results of the current study and findings from the research of Robert Morris University applicants, a shortage in the number of CIS/IT professionals during the next ten years is a realistic assumption. Using Robert Morris University as a barometer, the need to increase the applicant pool (and ultimately, the enrollment in CIS/IT programs) is a major challenge. One very prudent way to respond to the shortage of applicants is to examine and be prepared to change curricular offerings to address the dramatic changes in technology and student needs.

Curriculum change and adjustment to program format is not new to Robert Morris University. By recognizing new trends, the University has maintained a growing enrollment until the recent enrollment decreases that have occurred in the past few years. The current decline in student enrollment and the projected employment demand, as indicated by Department of Labor projections, forces the University to renew its recruitment efforts.

Recently, the most dramatic change instituted by the University was a delineation of specific CIS/IT majors that allows for more technology tracks and concentrations. Salient examples of these changes are the inclusion of tracks related to web design and network administration. In addition, new areas of concentration are being developed that focus on advanced web applications, network security, data warehousing, data mining, IT project management, and competitive intelligence.

New programs instituted by the University are highlighted by the innovative offering of a Doctor of Science Degree in Information Systems and Communications. This doctoral degree is a three year, cohort-based program that is sufficiently flexible to allow working professionals to continue their studies toward an advanced degree (1). This innovative program is now in its fourth year of existence and recent doctoral graduates are leveraging their knowledge and experience from the program in a variety of CIS/IT positions. Further, these noteworthy positions include opportunities in consulting, training, and executive management.

As universities continue to strategically address the future of technology and technology education, changes in curriculum and recruitment efforts will be necessary to attract new applicants and grow enrollment. Based on the current and aforementioned research, ample positions exist and will continue to exist in CIS/IT-related fields. Bright students, combined with innovative CIS and IT degree programs, will be well prepared to take advantage of these emerging career opportunities.

\section{REFERENCES}

1. Caputo, D. J., \& Kohun, F. J. (2003). "Women in information technology: New connections in the Internetbased enterprise". Journal of Business and Economics Research, 1(5), 41-46.

2. Daggett, W. R. (2001). Jobs and the skills gap. Retrieved May 12, 2004, from International Center for Leadership in Education Web Site: http://www.leadered.com/pdf/Job-Skills\%20Gap\%20White\% 20Paper PDF.pdf

3. Goodwin, B. (2004, March 9). "Future skills gap fear as students shun IT degrees". Computer Weekly, p. 12.

4. Kasler, D. (2004, April 26). "Outsourcing reaps winners, losers in the U.S. economy". Knight Ridder Tribune Business News, p. 1.

5. Leonard, B. (2002). Report reopens debate about shortage of IT workers. HR Magazine, 47(9), 24, 27.

6. $\quad$ Melymuka, K. (2004). "Stay just a little bit longer". Computerworld, 38(10), 46.

7. Piazza, P. (2002). "Wanted: information security experts". Security Management, 46(2), 37.

8. Porter, E. (2004, April 28). "Send jobs to India? U.S. companies say it's not always best". The New York Times, p. A1. 
9. Sujdak, E. J. (2002). "Impact of the shortage of IT professionals on logistics and supply chain management". Logistics Spectrum, 36(2), 15-21.

10. U.S. Department of Education. (2002, November). Table 252. Bachelor's degrees conferred by degreegranting institutions, by discipline division: 1970-71 to 2000-01. Retrieved May 14, 2004, from National Center for Education Statistics Web Site: http://nces.ed.gov/programs/digest/d02/tables/dt252.asp

11. U.S. Department of Labor. (2004, July). Table CES5000000001. National employment, hours and earnings: 1994-2004. Retrieved July 12, 2004, from U.S. Department of Labor Web Site: http://www.bls.gov/webapps/legacy/cesbtab1.htm

12. Vowler, J. (2003, June 10). "Importing skills: at what cost to the future?" Computer Weekly, p. 31.

\section{NOTES}

